\section{Pathogens fight back}

$\mathrm{O}$ pportunistic infections are thought to be caused by pathogens that are generally weaker than other organisms (i.e., have lower virulence) but are able to invade weakened hosts. It has also been suggested that bacteria s. regulate the expression of virulence factors depending on the 要 chance of successful invasion. ${ }^{1}$ However, the process whereby bacteria sense changes in the host $\stackrel{-1}{\circ}$ immune system is only now be$\AA$ coming better understood.

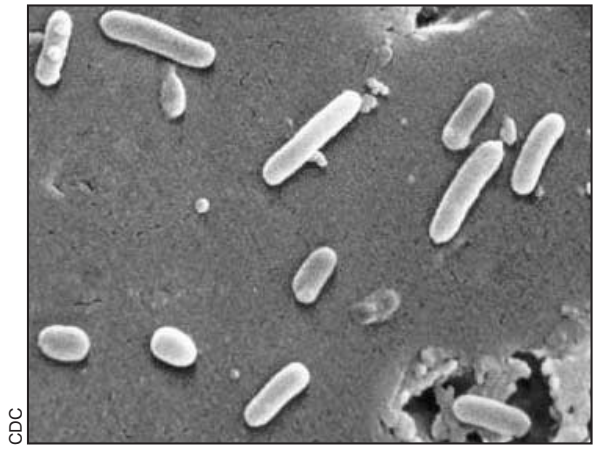

Pseudomonas aeruginosa
Pseudomonas aeruginosa is an opportunistic pathogen that has become a major focus of research owing to its growing resistance to antibiotics. It is a low-virulence organism in immunocompetent hosts, but in immnocompromised patients $P$. aeruginosa can cause a variety of severe infections. Infections are seen most notably in the respiratory tract, where the pathogen is largely responsible for exacerbations of cystic fibrosis; the skin, where it is the most common cause of burn-related sepsis; and the urinary tract.

New research by Licheng $\mathrm{Wu}$ and colleagues reveals that $P$. aeruginosa may actually use the host's immune system to become more invasive. ${ }^{2}$ The authors found that interferongamma (IFN- $\gamma$ ), a cytokine released by the immune system's T-cells to help clear bacteria, is recognized by $P$. aeruginosa . They found that when IFN- $\gamma$ binds to bacteria, virulence factors are activated, thereby providing a countermeasure to the activation of the host immune system.

It has long been known that host immune cells have receptors that recognize bacteria so that the immune response can be activated. It is logical to think that bacteria may in turn have receptors that recognize the immune system for the purpose of monitoring its activation. As the effectiveness of antibiotics wanes, this revelation may help in the development of new ways to suppress bacterial virulence. - David Secko, Vancouver

\section{References}

1. Mekalanos JJ. Environmental signals controlling expression of virulence determinants in bacteria. 7 Bacteriol 1992;174(1):1-7.

2. Wu L, Estrada O, Zaborina O, Bains M, Shen L, Kohler JE, et al. Recognition of host immune activation by Pseudomonas aeruginosa. Science 2005; 309(5735):774-7.

\title{
Link between porphyria and fasting uncovered
}

$\mathrm{T}$ he madness of King George III has been attributed to acute intermittent porphyria, an inherited genetic disorder of the heme biosynthesis pathway. Acute attacks of porphyria result in neuropsychiatric dysfunction and are often brought on by fasting or drugs, most notably sulfonamides and barbiturates. $\mathrm{Al}$ though episodes of the disease can be treated with heme infusion and glucose, the mechanism whereby acute porphyria is precipitated remains unclear.

New research by Christoph Handschin and colleagues reveals a missing molecular link that helps explain the mystery. ${ }^{1}$

These researchers found that fasting increases the level of a $\stackrel{5}{\circ}$ protein, proliferator-activated receptor $\gamma$ coactivator $1 \alpha$ $\AA$ (PGC-1 $\alpha$ ), which is involved in creating glucose in the liver. They also found that this protein regulates a key enzyme in the heme biosynthesis pathway, 5 -aminolevulinate synthase (ALAS-1). Increased levels of PGC- $1 \alpha$ resulted in increased production of ALAS-1. This in turn led to a build-up of precursor heme molecules, which, in mice, caused acute attacks of porphyria. The discovery reveals why glucose administration is helpful, since glucose can return PGC- $1 \alpha$ levels to normal. However, the role of PGC- $1 \alpha$ seems to be restricted to fasting-induced porphyria, since there was no effect when barbiturates were administered.

This discovery may lead to new treatments that allow patients to regulate their weight through diet without fear of

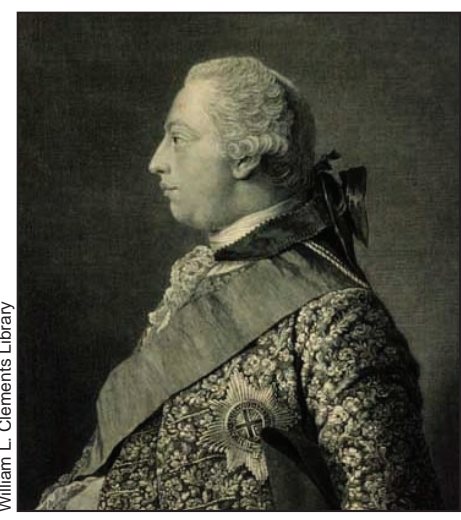

King George III

acute episodes that result from decreased energy intake. David Secko, Vancouver

\section{Reference}

1. Handschin C, Lin J, Rhee J, Peyer A Chin S, Wu PH, et al. Nutritional regulation of hepatic heme biosynthesis and porphyria through PGC- $1 \alpha$. Cell 2005;122:505-15. 